\title{
Impact of ALK variants on brain metastasis and treatment response in advanced NSCLC patients with oncogenic ALK fusion
}

\author{
Meng Qiao" ${ }^{1 \#}$, Chao Zhao ${ }^{2 \#}$, Qian Liu ${ }^{1}$, Yan Wang ${ }^{1}$, Jingyun Shi ${ }^{3}$, Terry L. $\mathbf{N g}^{4}$, Fei Zhou ${ }^{1}$ Xuefei $\mathrm{Li}^{2}$, \\ Tao Jiang ${ }^{1}$, Shuo Yang ${ }^{1}$, Guanghui Gao ${ }^{1}$, Anwen Xiong ${ }^{1}$, Jiayu $\mathrm{Li}^{1}$, Wei Li ${ }^{1}$, Fengying $\mathrm{Wu}^{1}$, Xiaoxia Chen ${ }^{1}$, \\ Chunxia Su${ }^{1}$, Shengxiang Ren ${ }^{1 *}$, Caicun Zhou ${ }^{1 *}$, Jun Zhang ${ }^{5}$ \\ ${ }^{1}$ Department of Medical Oncology, ${ }^{2}$ Department of Lung Cancer and Immunology, ${ }^{3}$ Department of Imaging, Shanghai Pulmonary Hospital, Tongji \\ University School of Medicine, Shanghai, China; ${ }^{4}$ Division of Medical Oncology, University of Ottawa, Ottawa, Canada; ${ }^{5}$ Division of Hematology, \\ Oncology and Blood \& Marrow Transplantation, Department of Internal Medicine, Holden Comprehensive Cancer Center, University of Iowa \\ Carver College of Medicine, Iowa City, IA, USA \\ Contributions: (I) Conception and design: M Qiao, C Zhao, S Ren, C Zhou; (II) Administrative support: C Zhou, S Ren; (III) Provision of study \\ materials or patients: C Zhou, S Ren; (IV) Collection and assembly of data: M Qiao, C Zhao, Q Liu, T Jiang, Y Wang, F Zhou, G Gao, A Xiong, \\ J Li, W Li; (V) Data analysis and interpretation: X Li, T Jiang, S Yang, J Shi, F Wu, X Chen, C Su, TL Ng, J Zhang; (VI) Manuscript writing: All \\ authors; (VII) Final approval of manuscript: All authors. \\ \#These authors contributed equally to this work. \\ *These authors contributed equally for the senior authorship. \\ Correspondence to: Prof. Caicun Zhou. Department of Medical Oncology, Shanghai Pulmonary Hospital \& Thoracic Cancer Institute, Tongji \\ University School of Medicine, No. 507, Zheng Min Road, Shanghai 200433, China._Email: caicunzhou_dr@163.com.
}

Background: To investigate the impact of ALK variants on the features of brain metastases (BM), the outcome of chemotherapy and targeted therapy using crizotinib, as well as the progression pattern in patients with ALK fusion.

Methods: Patients with ALK fusion were retrospectively collected from January 2013 to July 2017 in Shanghai Pulmonary Hospital. ALK rearrangements were identified via ARMS-PCR. ALK variants were identified via Sanger Sequencing.

Results: A total of 135 patients and 41 with brain metastasis were identified. Radiological features showed that the patients with ALK variant 1 had a larger BM size compared with patients with ALK non-variant 1 (median tumor size: 16.89 vs. $11.01 \mathrm{~mm}, \mathrm{P}=0.031$ ). Similar time to treatment failure (TTF) was observed in patients with ALK variant 1 and non-variant 1 who received first-line crizotinib (median TTF: 15.7 vs. 13.8 months, $\mathrm{HR}=0.75, \mathrm{P}=0.34$ ). Patients with $\mathrm{ALK}$ variant 1 who had baseline $\mathrm{BM}$ had significantly shorter TTF than non-variant 1 with baseline BM when treated with first-line crizotinib (median TTF: 9.1 vs. 14.9 months, $\mathrm{HR}=2.68, \mathrm{P}=0.037$ ). In patients treated with chemotherapy, ALK variant 1 was associated with inferior TTF (median TTF: 5.6 vs. 8.1 months, HR =1.66, $\mathrm{P}=0.039$ ). Progression pattern was similar between ALK variant 1 and non-variant 1.

Conclusions: Patients with ALK variant 1 and baseline BM had inferior TTF on first-line crizotinib treatment and presented with more aggressive radiological features. Patients with ALK non-variant 1 had better clinical outcome on first-line chemotherapy.

Keywords: Anaplastic lymphoma kinase (ALK); crizotinib; chemotherapy; treatment response; brain metastasis (BM)

Submitted Aug 20, 2019. Accepted for publication Jul 14, 2020.

doi: $10.21037 /$ tlcr-19-346

View this article at: http://dx.doi.org/10.21037/tlcr-19-346 


\section{Introduction}

Anaplastic lymphoma kinase (ALK) gene rearrangements were first discovered in 2007 and account for $2-7 \%$ of non-small cell lung cancer (NSCLC) $(1,2)$. Thereafter, several studies have established the role of crizotinib as standard of care in later line, $2^{\text {nd }}$ line and first line setting of advanced NSCLC patients with ALK fusion (3-7). However, nearly all patients receiving crizotinib inevitably progress, with the majority of them presenting with disease progression in the central nervous system (CNS) (8). Several $2^{\text {nd }}$ or $3^{\text {rd }}$ generation ALK inhibitors such as ceritinib (9), alectinib $(10,11)$, brigatinib (12) and lorlatinib (13) with better CNS penetration, were developed and have demonstrated superior efficacy over crizotinib for both extracranial and intracranial disease $(14,15)$. Besides ALK inhibitors, pemetrexed-based chemotherapy is potentially more efficacious than other chemotherapy against lung cancer with ALK fusion (16). However, response to these treatments is heterogeneous and precisive strategies are needed to further improve the outcome of patients with ALK fusion.

Echinoderm microtubule-associated protein-like 4 (EML4) is the most common fusion partner to ALK. To date, 15 EML4-ALK variants have been identified. The most common are variant 1 [v1; exon 13 of EML4 fused to exon 20 of ALK $(\mathrm{E} 13 ; \mathrm{A} 20)]$ and variant $3 \mathrm{a} / \mathrm{b}$ [exon $6 \mathrm{a} / \mathrm{b}$ of EML4 fused to exon 20 of ALK (E6a/b;A20)] (17,18). More and more evidences suggest that ALK fusion variants may have biologic and clinical implications in ALK-positive lung cancer (19-26). For example, Yoshida et al. found crizotinib had better efficacy in patients with EML4-ALK variant 1 than those with nonvariant 1 (21). Furthermore, Lin et al. revealed that variant $3 \mathrm{a} /$ b were associated with G1202R, an ALK mutation that confers resistance to crizotinib and all $2^{\text {nd }}$ generation ALK TKIs (e.g., ceritinib, alectinib and brigatinib), which suggested the link between ALK fusion variant and clinical outcome (25). Thus, analyzing ALK variants might help provide new insight in the era of precision medicine.

ALK gene rearranged lung cancer have a high incidence of $\mathrm{BM}$ and exploring the characteristics including ALK variants in ALK+ patients with baseline BM might help guide therapeutic strategy $(8,16,27)$. Here, in order to have a better understanding of clinical impact of ALK variants on $\mathrm{BM}$, we comprehensively investigated the association of ALK variants with the feature of brain metastasis, as well as the efficacy of crizotinib and chemotherapy in 135 Chinese advanced NSCLC patients with ALK fusions.
We present the following article in accordance with the STROBE Reporting Checklist (available at http://dx.doi. org/10.21037/tlcr-19-346).

\section{Methods}

The study was conducted in accordance with the Declaration of Helsinki (as revised in 2013) and was approved by the Ethics Committee of Shanghai Pulmonary Hospital, Tongji University School of Medicine (No. K18089-1). Because of the retrospective nature of the research, the requirement for informed consent was waived.

\section{Study population and study design}

As shown in Figure 1A, we enrolled 235 patients with positive ALK-rearrangement from January 2013 to July 2017 in Shanghai Pulmonary Hospital. In total, 41 patients had confirmed BM at baseline. Among them, 8 patients had brain MRI data but were lack of evaluation of treatment response. This was due to either to be enrolled in doubleblind clinical trials, or no further anti-cancer therapy, or lost follow-up. Therefore, 33 patients with baseline BM were included as a subgroup to compare time to treatment failure (TTF) and objective response rate (ORR) between variant $1 v s$. non-variant 1 in both crizotinib-treated and chemo-treated settings. In addition, 6 out of the 41 patients had their BM confirmed in other hospitals but not ours. Therefore, only the remaining 35 patients with both the baseline BM and available MRI data were included as an exploratory subgroup to compare (I) radiological features; (II) neurological symptoms; (III) the graded prognostic assessment (GPA) score between variant $1 v s$. non-variant 1 .

Among 235 patients, 100 patients were excluded owing to either ineligible variant detection results (PCR product was not abundant to perform Sanger Sequencing), missing information on first-line lung cancer treatment (the patient made treatment decision at a peripheral hospital), or lack of survival data. Finally, 135 patients with either crizotinib or chemotherapy as their first-line treatment were included to compare (I) TTF and ORR; (II) progression pattern between variant $1 v s$. non-variant 1 in both crizotinibtreated and chemo-treated groups.

\section{Data reporting and acquisition}

TTF was defined as the time from the start of crizotinib treatment or chemotherapy to the date of treatment 

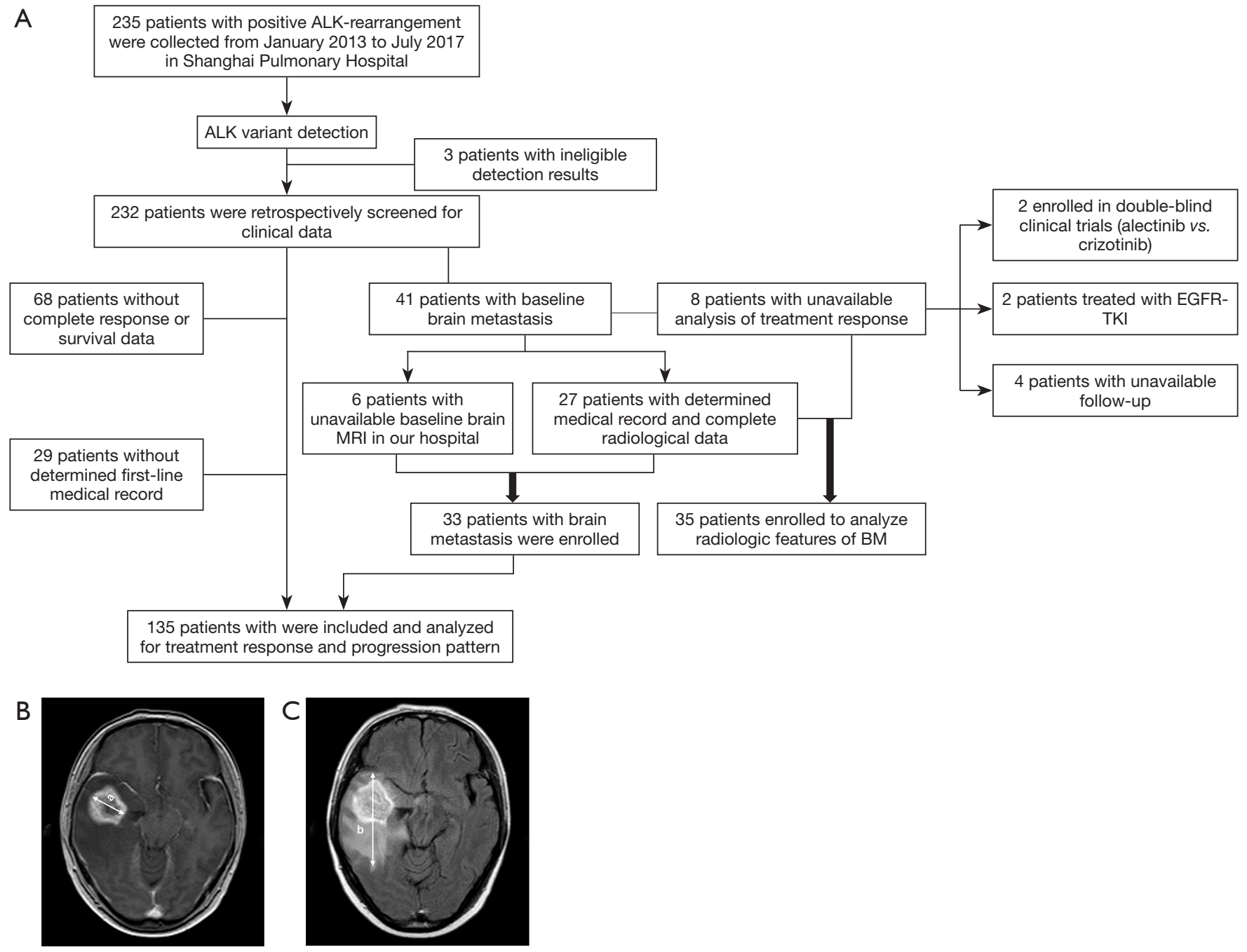

Figure 1 Summary of study design and measurement of PTBE. (A) Flow chart of the study design; (B,C) PTBE is the difference in maximum diameter of tumor in T2-weighted MRI image (right: bidirectional arrow labeled "b") and maximum diameter of tumor in T1weighted MRI image (left: bidirectional arrow labeled "a").

discontinuation for any reason (including switching treatment strategy, death, whichever occurred first). ORR was calculated as percentage of patients with evaluated complete response (CR) or partial response (PR).

To investigate the progression pattern, patients enrolled in this study routinely got chest CT scan every 2 months, brain MRI every 6 months, bone scan every 6 months and abdominal ultrasound every 6 months. Any radiological examination was applied whenever related symptoms occurred.

\section{Radiological features of $B M$}

The brain images obtained by MRI were collected. All scans were performed on the same 1.5 Tesla MRI machine (United Imaging Health-care, Shanghai). Three variables were measured: (I) number of BMs; (II) size of BM; (III) sum of $\mathrm{BM}$ size; (IV) size of peritumoral brain edema (PTBE). For multiple brain tumors, the BM size was defined using the longest diameter of the largest lesion in one dimension on T1-weighed images. PTBE was defined as the subtraction of diameter measured on T1-weighed imaging from that measured on corresponding $\mathrm{T} 2$-weighed images (Figure $1 B, C$ ). If no edema was observed, the size of PTBE was defined as zero (Figure S1). The size of the tumor and PTBE were measured by two experienced oncologists and one radiologist, and averaged eventually. 


\section{Graded prognostic assessment (GPA)}

The GPA is a validated assessment scale for lung cancer patients with BM (28). Four prognostic factors comprise the GPA: Karnofsky performance score (KPS) (0: KPS $<70$, 0.5: KPS $=70-90,1.0$ : KPS $>90)$, age (0: age $>60,0.5$ : age $=50-60,1:$ age $<50)$, presence of extracranial metastasis (ECM) (0: ECM yes or 1: ECM no), and the number of BM (0: >3 BM, 0.5: 2-3 BM,1: 1 BM). The GPA score showed good prognostic discrimination, and depending on the GPA score, lung cancer patients with BM in this study had a median overall survival (OS) ranging from 3.02 to 14.78 months (29).

\section{Detection of ALK rearrangements and variants}

The Amplification Refractory Mutation System (ARMS) was adopted to detect ALK fusion using the Human AmoyDx EML4-ALK Fusion Gene Diagnostic Kit (Amoy Diagnostics Co, Ltd). ALK variants were detected via Sanger sequencing of PCR product. The detailed procedures were performed as previously described (30-35).

\section{Statistical analysis}

All data were analyzed by using the Statistical Package for Social Science (SPSS) software (version 23.0 for Mac) and GraphPad Prism software (Version 6 for Mac). Differences in baseline clinical characteristics between groups (variant $1 v s$. non-variant 1 ) were analyzed using Chi-square test or Fisher's exact test. The Kaplan-Meier method was used to analyze the survival probability and log-rank test was used to calculate the significance of differences. Cox proportional hazard model was applied for the univariate and multivariate analyses to calculate the hazard rations (HR) and $95 \%$ confidence intervals (95\% CI). P values in this article were two-sided and considered statistically significant when less than 0.05 .

\section{Results}

\section{Distribution of ALK variants and the association with clinical characteristics}

In total, 135 patients with known ALK variant and medical record were analyzed. As shown in Figure 2A, the most frequent was ALK variant 1 (E13;A20) in 61 patients $(45.2 \%)$, followed by variant $3 \mathrm{a} / \mathrm{b}(\mathrm{E} 6 ; \mathrm{A} 20 / \mathrm{E} 6$ ins $33 ; \mathrm{A} 20)$ in 51 patients $(37.8 \%)$ and variant $2(\mathrm{E} 20 ; \mathrm{A} 20)$ in 17 patients
(12.6\%). Other variants included 3 patients with variant V5(5') (E18;A20), 2 with variant 5a (E2;A20) and one with variant $8 \mathrm{a} / \mathrm{b}(\mathrm{E} 17 ; \mathrm{A} 20)$ (Baseline characteristics of patients listed in Table 1). In the overall study cohort, median age was 53.4 (28 to 80$)$ years old and $48.9 \%$ (66/135) were male, $73.3 \%$ (99/135) were never-smokers, 91.9\% (124/135) had lung adenocarcinoma, and $8.1 \%(11 / 135)$ had recurrence after initial diagnosis of early stage disease. As first-line therapy, $51.9 \%(70 / 135)$ received chemotherapy and $48.1 \%$ $(65 / 135)$ received crizotinib. Comparing the variant 1 and non-variant 1 cohorts, there were no significant differences observed with regard to age $(\mathrm{P}=0.500)$, gender $(\mathrm{P}=0.148)$, ECOG PS ( $\mathrm{P}=0.183)$, histology $(\mathrm{P}=0.110)$, and smoking status $(\mathrm{P}=0.498)$. In total, 33/135(24.4\%) patients had baseline BM before treatment. In the overall study cohort, 15/33 (45.4\%) patients with BM, 4/14 (28.6\%) patients with bone metastasis, and 6/12 (50\%) patients with liver metastasis were variant 1 . In our study cohort, there was no statistical significance in baseline incidence of metastasis between variant 1 and non-variant 1 (BM: $\mathrm{P}=0.971$, bone metastasis: $\mathrm{P}=0.187$, liver metastasis: $\mathrm{P}=0.726$ ).

\section{Radiological features associated with ALK variants in patients with baseline BM}

In patients with BM, there was no statistical significance in clinical characteristics between variant 1 and non-variant 1 (Table S1). We further examined the radiological features according to ALK variants (proportion of patients with $\leq 3 \mathrm{BM}$, symptomatic $\mathrm{BM}$ at baseline, $\mathrm{BM}$ size, sum of $\mathrm{BM}$ size and PTBE) in patients with baseline $\mathrm{BM}(\mathrm{N}=35)$ (Figure $2 B$ ). There was no significant difference in the proportion of patients with three BMs or less [11 (78.6\%) patients in variant 1 subgroup and $16(76.2 \%)$ patients in non-variant 1 subgroup]. Overall, 51.4\% (18/35) ALK+ patients with baseline BM suffered from neurological symptoms, defined as headache, dizzy, nausea, vomiting, and etc. Of those cases, $64.3 \%(9 / 14)$ of patients with ALK variant 1 had neurological symptoms related to BMs compared to $42.8 \%(9 / 21)$ in the non-variant 1 group $(\mathrm{P}=0.21)$. In addition, the patients with ALK variant 1 had larger BM size (median BM size: 16.89 vs. $11.01 \mathrm{~mm}$, $\mathrm{P}=0.031)$ and numerically higher CNS burden (30.32 vs. $21.98 \mathrm{~mm}, \mathrm{P}=0.272)$ together with wider PTBE (17.94 vs. $12.80 \mathrm{~mm}, \mathrm{P}=0.447$ ) compared to patients with ALK non-variant 1 . No significant difference was observed in constituent ratio of GPA score between two groups $(\mathrm{P}=0.934)$. 


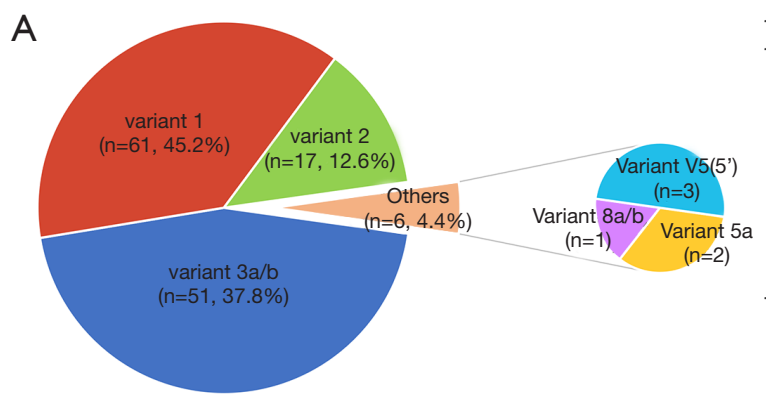

\begin{tabular}{ccc}
\hline & Fusion subtypes & No. of patients \\
\hline EML4-ALK-variant 1 & E13; A20 & 61 \\
EML4-ALK-variant 3a/b & E6;A20/E6ins33;A20 & 42 \\
& E6;A20 & 4 \\
& E6ins33;A20 & 5 \\
EML4-ALK-variant 2 & E20;A20 & 17 \\
EML4-ALK-variant 5a & E2;A20 & 2 \\
EML4-ALK-variant V5(5') & E18;A20 & 3 \\
EML4-ALK-variant 8a/b & E17;A20 & 1 \\
\hline
\end{tabular}

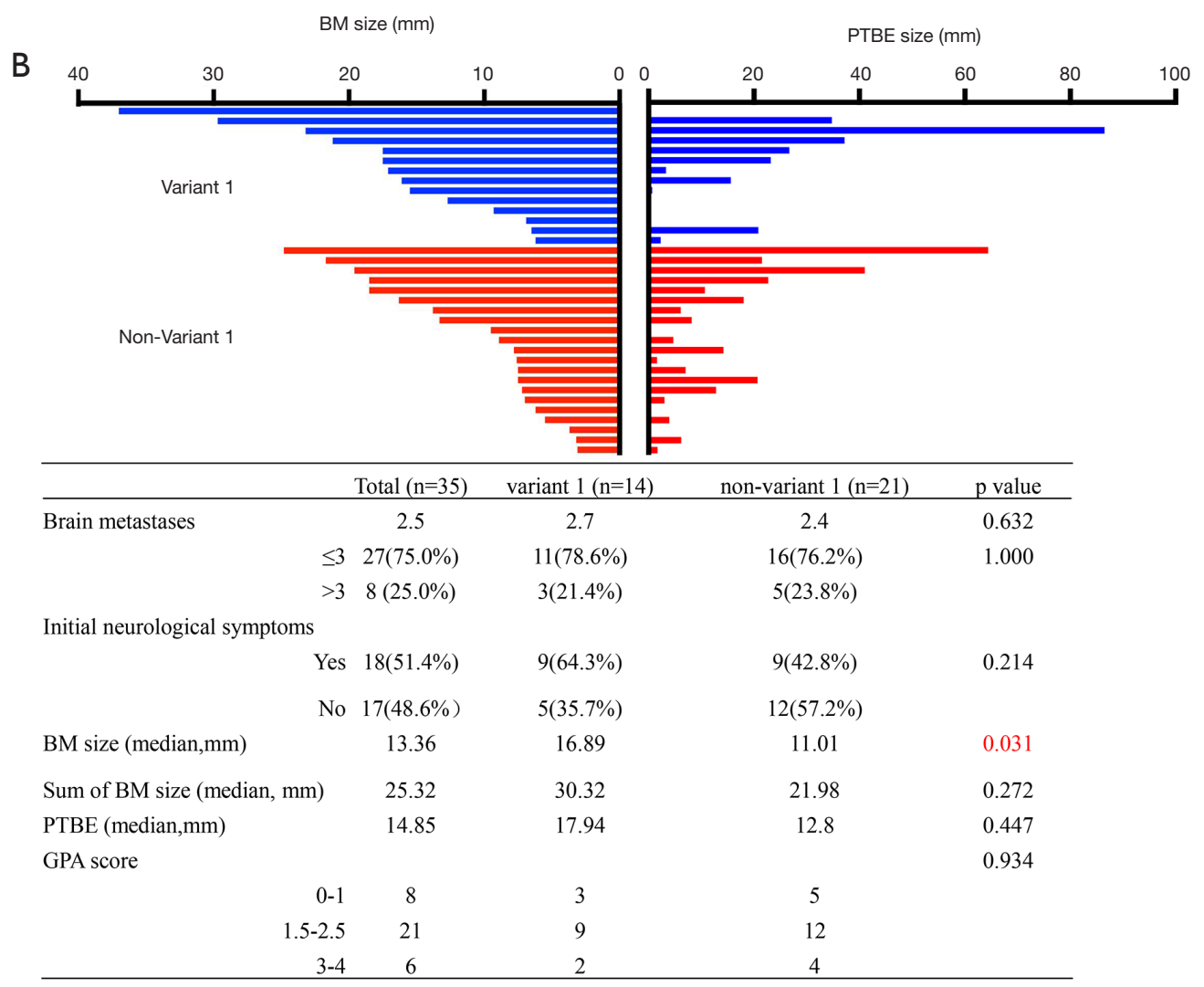

Figure 2 Overview of ALK variants and characteristics of radiological features in ALK positive patients with BM. (A) The distribution of ALK fusion variants; (B) the radiological features (BM size, PTBE) of brain tumor size in group of ALK-variant 1 and non-variant 1. Each blue bar represents an individual patients with variant 1 and red bar represents an individual with non-variant 1 . The length of the bar represents either BM size (left extended) or PTBE size (right extended). The followed table summarized the characteristics related to BM in variant 1 and non-variant 1.

\section{Impact of ALK-variants on efficacy of crizotinib}

Patients who received crizotinib as first-line treatment strategy had longer TTF than those who had chemotherapy (median TTF: 13.8 vs. 6.3 months, $\mathrm{HR}=0.43, \mathrm{P}<0.01$, Figure $3 A$ ). There was no significant TTF difference between variant 1 and non-variant 1 in the subgroup treated with first-line crizotinib (Figure 3B). Both ORR and the
DCR were not significantly different between variant 1 and non-variant 1 in the crizotinib-treated group (Table S2). Univariate and multivariate analysis showed that only ECOG PS and patient sex had a significant impact on TTF. None of the other variables including ALK variant were associated with TTF (Table 2).

Patients with baseline BM had a median TTF of 12.7 months treated with crizotinib, compared to 
Table 1 Clinical characteristics of included patients

\begin{tabular}{|c|c|c|c|c|}
\hline Characteristic & Total (N=135) (\%) & Variant $1(\mathrm{~N}=61)(\%)$ & Non-variant $1(\mathrm{~N}=74)(\%)$ & $P$ value \\
\hline Gender & & & & 0.148 \\
\hline Male & $66(48.9)$ & $34(55.7)$ & $32(43.2)$ & \\
\hline Female & $69(51.1)$ & $27(44.3)$ & $42(56.8)$ & \\
\hline $0-1$ & $125(92.6)$ & $59(96.7)$ & $66(89.2)$ & \\
\hline $2-3$ & $10(7.4)$ & $2(3.3)$ & $8(10.8)$ & \\
\hline Histology & & & & 0.110 \\
\hline Adenocarcinoma & $124(91.9)$ & $53(86.9)$ & $71(95.9)$ & \\
\hline Current/former smokers & $36(26.7)$ & $18(29.5)$ & $18(24.3)$ & \\
\hline Never-smokers & $99(73.3)$ & $43(70.5)$ & $56(75.7)$ & \\
\hline Stage & & & & 1.000 \\
\hline Unresected IIIB-IV & 124 (91.9) & $56(91.8)$ & $68(91.9)$ & \\
\hline Postoperative recurrent & $11(8.1)$ & $5(8.2)$ & $6(8.1)$ & \\
\hline First-line treatment strategy & & & & 0.827 \\
\hline Chemotherapy & $70(51.9)$ & $31(50.8)$ & $39(52.7)$ & \\
\hline Crizotinib & $65(48.1)$ & $30(49.2)$ & $35(47.3)$ & \\
\hline Baseline brain metastasis & & & & 0.971 \\
\hline Yes & $33(24.4)$ & $15(24.6)$ & $18(24.3)$ & \\
\hline No & $102(75.6)$ & $46(75.4)$ & $56(75.7)$ & \\
\hline Baseline bone metastasis & & & & 0.187 \\
\hline Yes & $14(10.3)$ & $4(6.6)$ & $10(13.5)$ & \\
\hline No & $120(88.9)$ & $57(93.4)$ & $64(86.5)$ & \\
\hline Baseline liver metastasis & & & & 0.726 \\
\hline Yes & $12(8.9)$ & $6(9.8)$ & $6(8.1)$ & \\
\hline No & $123(91.1)$ & $55(90.2)$ & $68(91.9)$ & \\
\hline
\end{tabular}


A
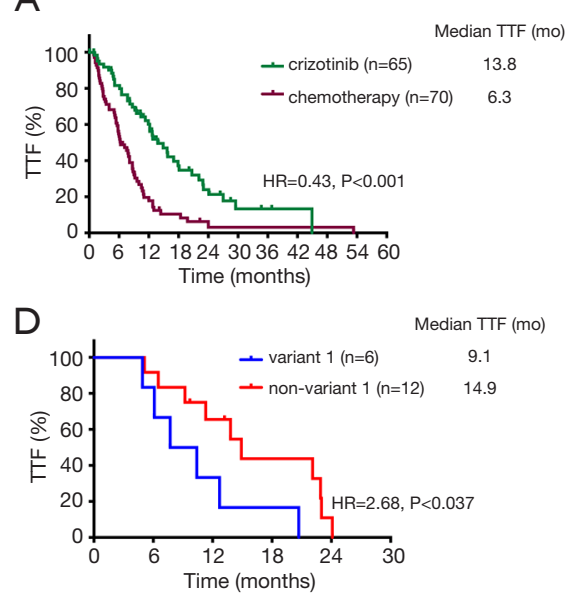

B

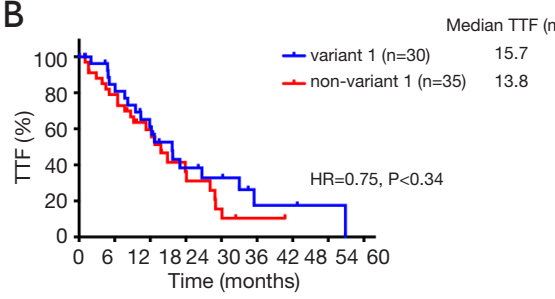

$E$

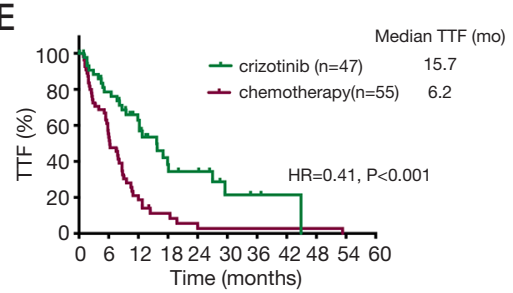

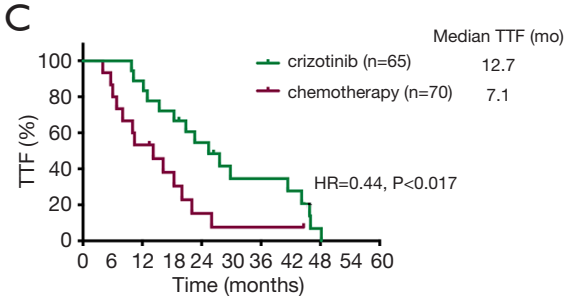

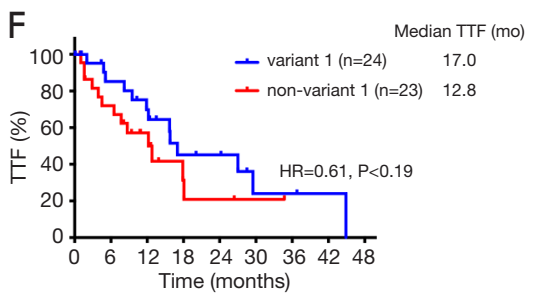

Figure 3 Time to treatment failure (TTF) in (A) overall population; (B) patients treated with crizotinib as the first-line therapy; (C) patients with baseline brain metastasis; (D) patients with baseline brain metastasis and treated with crizotinib as first-line therapy; (E) patients without baseline brain metastasis; (F) patients without baseline brain metastasis and treated with crizotinib as first-line therapy.

Table 2 Univariate and multivariate analyses of clinical parameters on TTF in patients with ALK rearrangement-positive NSCLC treated with crizotinib

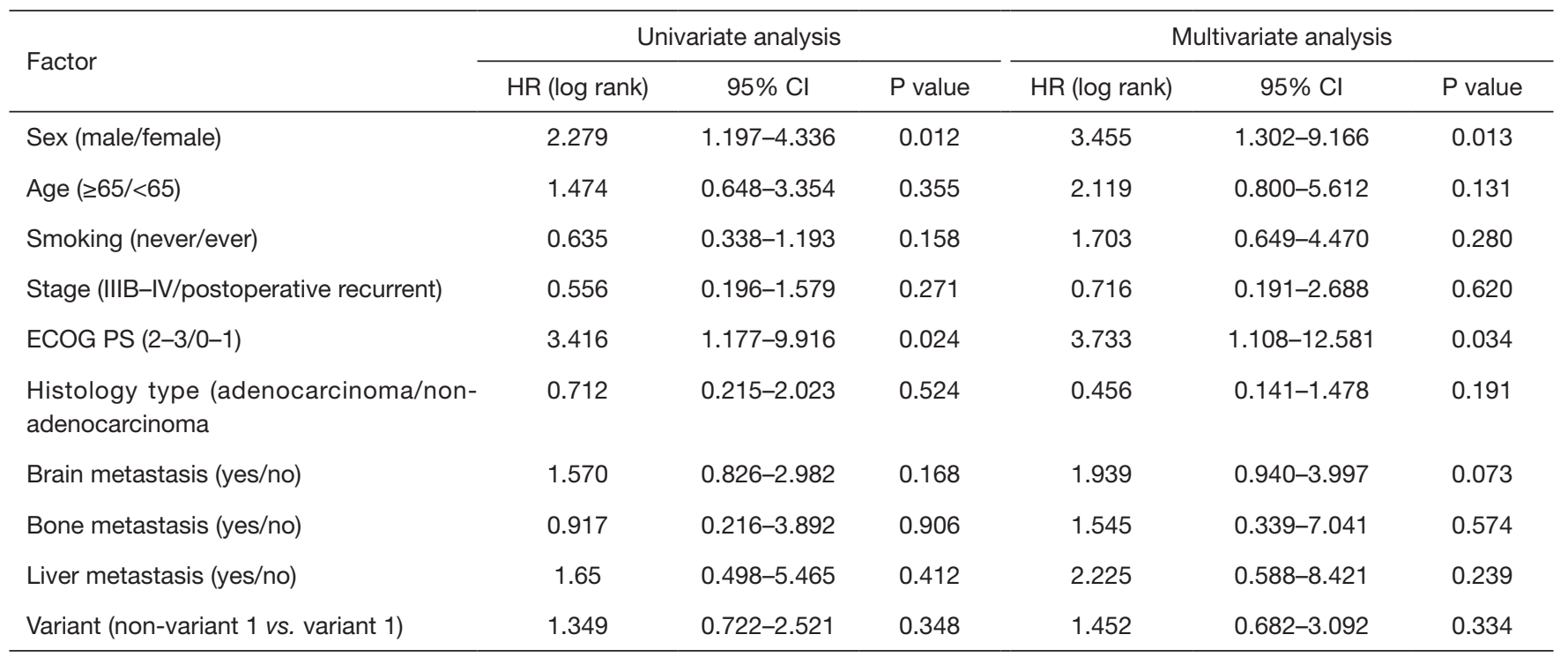

7.1 months in the chemotherapy-treated group $(\mathrm{P}=0.017$, Figure 3C). Patients with variant 1 and baseline $\mathrm{BM}$ had a significantly shorter TTF than non-variant 1 on first-line crizotinib ( $\mathrm{HR}=2.68, \mathrm{P}=0.037$, Figure $3 D$ ). Regardless of first-line treatment strategy, patients with variant 1 and baseline BM had significantly lower ORR than patients with non-variant $1(20 \%$ vs. $66.7 \%, \mathrm{P}=0.007)$ and numerically lower in crizotinib-treated group $(50.0 \%$ vs. $75.0 \%$, $\mathrm{P}=0.596$, Figure S2). In patients without baseline metastases, patients treated with crizotinib had median TTF of 15.7 months and no statistically significant difference in TTF was observed between variant 1 and non-variant 1 (median TTF: 17.0 vs. 12.8 months, HR 0.61, $\mathrm{P}=0.19$ ) (Figure 3E,F).

\section{Impact of ALK-variants on efficacy of chemotherapy}

A total of 70 patients received chemotherapy as their 

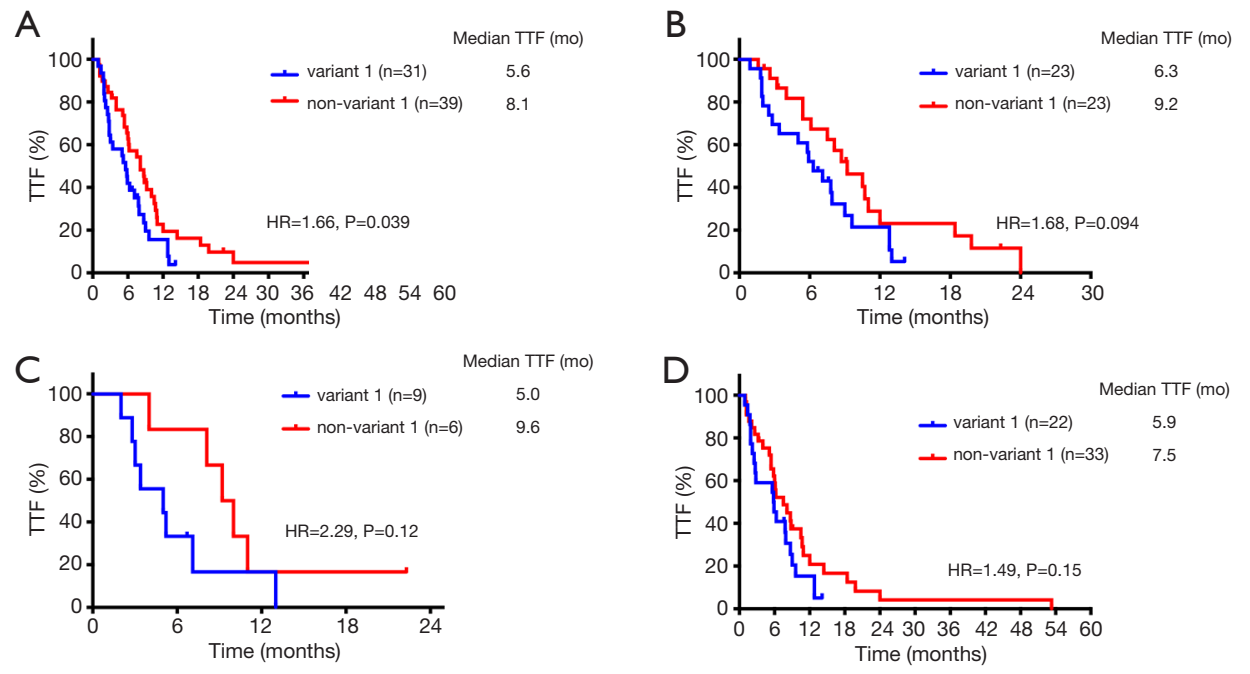

Figure 4 Time to treatment failure (TTF) outcomes in $A L K$ variant 1 versus non-variant 1 in patients treated with (A) any first-line chemotherapy; (B) first-line pemetrexed-based chemotherapy; (C) patients with baseline brain metastasis and treated with first-line chemotherapy; (D) patients without baseline brain metastasis and treated with first-line chemotherapy.

first-line treatment strategy. Patients with $A L K$ variant 1 had a significantly inferior TTF compared to those with ALK non-variant 1 (median TTF: 5.6 vs. 8.1 months, HR $=1.66, \mathrm{P}=0.039$ ) (Figure $4 A$ ). In the subgroup receiving pemetrexed-based chemotherapy, patients with variant 1 had a TTF of 6.3 months, whereas patients with nonvariant 1 had a TTF of 9.2 months $(\mathrm{P}=0.094)$ (Figure 4B). Otherwise, ORR and DCR were similar between variant 1 and non-variant 1 cohorts receiving first-line chemotherapy (Table S3). In the ALK variant 1 cohort, patients receiving $1^{\text {st }}$ line chemotherapy $(\mathrm{N}=31)$ had numerically inferior TTF compared to non-variant 1 , regardless of whether they had BM at baseline, but the difference was not statistically significant $(\mathrm{P}=0.12$ and $\mathrm{P}=0.15$, respectively, Figure $4 C, D)$. Other than ECOG PS, only non-variant 1 status was significantly associated with a longer TTF in both univariate analysis (vs. variant $1, \mathrm{HR}=0.579, \mathrm{P}=0.043$ ) and multivariate analysis (vs. variant $1, \mathrm{HR}=0.470, \mathrm{P}=0.009)$ (Table 3).

\section{Progression pattern according to variants}

Patterns of disease progression were separated into five categories: CNS progression, liver progression, bone progression, intrathoracic progression and other extrathoracic progression. Other extra-thoracic progression was defined as metastases occurring in the adrenal glands, spleen or extra-pulmonary lymph nodes. Overall, no significant difference in progression pattern was observed in variant 1 and non-variant 1 (Figure $S 3 A$ ). At the time of analysis, 55 patients who were once treated with crizotinib and 61 patients treated with chemotherapy exhibited progression of disease (PD), including 56 patients with ALK variant 1 (28 once received crizotinib; 28 received chemotherapy) and 60 patients with ALK non-variant 1 (first-line treatment: 27 received crizotinib; 33 received chemotherapy). However, there were no significant differences in the patients with intra-thoracic and extra-thoracic recurrence between the variant 1 and non-variant 1 group (Table S4, Figure S3B).

\section{Discussion}

This real-world study collected the largest cohort of $A L K$ positive patients and comprehensively investigated the association of $A L K$ variants with brain metastases together with clinical outcomes on first-line crizotinib and chemotherapy. We observed more aggressive radiological features (larger BM size and numerically larger area of PTBE) in those with ALK variant 1 than non-variant 1 . We found a numerically longer but not statistically significant difference of TTF in patients with ALK variant 1 and non-variant 1 in crizotinib-treated group (median TTF: 15.7 vs. 13.8 months, $\mathrm{P}=0.75$ ), while subgroup analysis showed that patients with ALK-variant 1 and baseline BM had significantly shorter TTF $(\mathrm{P}=0.037)$. Additionally, 
Table 3 Univariate and multivariate analyses of clinical parameters on TTF in patients with ALK rearrangement-positive NSCLC treated with chemotherapy

\begin{tabular}{|c|c|c|c|c|c|c|}
\hline Factor & \multicolumn{3}{|c|}{ Univariate analysis } & \multicolumn{3}{|c|}{ Multivariate analysis } \\
\hline Sex (male/female) & 0.699 & $0.417-1.170$ & 0.173 & 0.579 & $0.303-1.108$ & 0.099 \\
\hline Age $(\geq 65 /<65)$ & 0.821 & $0.371-1.817$ & 0.627 & 0.753 & $0.314-1.810$ & 0.527 \\
\hline Smoking (never/ever) & 1.031 & $0.541-1.967$ & 0.925 & 1.069 & $0.465-2.458$ & 0.875 \\
\hline ECOG PS (2-3/0-1) & 2.728 & $1.128-6.602$ & 0.026 & 2.748 & $1.008-7.492$ & 0.048 \\
\hline Histology type (adenocarcinoma/non-ade & 0.524 & $0.159-1.719$ & 0.286 & 0.610 & $0.138-2.695$ & 0.515 \\
\hline Brain metastasis (yes/no) & 0.969 & $0.523-1.795$ & 0.920 & 0.807 & $0.410-1.588$ & 0.535 \\
\hline Bone metastasis (yes/no) & 1.582 & $0.793-3.158$ & 0.193 & 1.992 & $0.898-4.420$ & 0.09 \\
\hline
\end{tabular}

patients with ALK non-variant 1 had longer TTF in the chemotherapy-treated group than patients with variant 1 (median TTF: 8.1 vs. 5.4 months, $\mathrm{P}=0.039$; multivariate analysis: $\mathrm{P}=0.009)$.

As far as we know, this is the first report on the association of ALK variants with the radiologic features of $\mathrm{BM}$. We found that the size of baseline metastasis in variant 1 group was larger than in non-variant 1 group (median TS: 16.89 vs. $11.01 \mathrm{~mm}, \mathrm{P}=0.031$ ) with numerically higher CNS burden and wider edema range. Additionally, patients with ALK variant 1 and baseline BM had a higher frequency $(64.3 \%)$ of neurologic symptoms related to BM than patients with ALK-non variant 1 (42.8\%). Previous studies demonstrated that the size of $\mathrm{BM}$ was positively associated with the thickness of PTBE and both factors were associated with worse survival outcome $(36,37)$. Although statistical significance regarding the size of PTBE was not reached owing to the limited sample size, it is suggested that patients with ALK-variant 1 and baseline BM likely have more aggressive $\mathrm{BM}$ radiographically and might be related to the different efficacy of crizotinib in this study. Our subgroup analysis showed that patients with baseline BM and ALK-variant 1 had a significantly worse TTF than those with non-variant 1 (9.1 vs. 14.9 months, $\mathrm{P}=0.037$ ) after the treatment of crizotinib.

The frequency of BM in treatment-naïve $A L K+$ NSCLC ranges from $20-40 \%$. The clinical outcome of ALK+ patients with baseline $\mathrm{BM}$ receiving crizotinib varied across different studies (PFS range, 7.0-21.2 months) (6,7,
38-40). It is conceivable that different ALK variant might explain the heterogeneity of treatment response in ALK patients with baseline BM. Although previous investigations including our current study indicated that variant 1 might have better crizotinib response than non-variant 1 but lack of significance $(22,23,25)$, Yoshida, et al. did report a significantly longer PFS to crizotinib in patients with variant $1(\mathrm{n}=19)$ versus non-variant $1(\mathrm{n}=16)$ (median PFS: 11.0 vs. 4.2 months, $\mathrm{P}<0.05)(21)$. The inconsistency might be due to lower percentage of patients with baseline BM in Yoshida's study (20\%) comparing to other studies including ours (ranging from $26 \%$ to $44.4 \%$ ) $(22,23,25)$.

The most frequent ALK variants were variant 1 (45.2\%) and variant $3 \mathrm{a} / \mathrm{b}(35.8 \%)$, which was consistent with the findings from previous publications (Table S5). In consistent with previous studies (20-25), similar baseline clinical characteristics between different ALK variants were found in our study. Previous studies including ours found that the level of thymidylate synthetase (TS) was lower in ALK-positive tumors (41) and correlated with enhanced sensitivity to pemetrexed than ALK-wild type tumors $(16,42)$. This present study found that ALK-non variant 1 had statistically significant longer TTF than ALK variant 1 in the chemotherapy-treated group (median TTF: $8.1 \mathrm{vs}$. 5.6 months, $\mathrm{P}=0.039$ ) and possibly longer TTF than ALK variant 1 in the pemetrexed-treated group (median TTF: 9.2 vs. 6.3 months, $\mathrm{P}=0.094$ ), although statistical significance for the latter comparison was not shown. In consistent with worse outcomes seen in ALK variant 1 patients treated with 
pemetrexed-based chemotherapy, an in-vitro study showed that the IC50 to pemetrexed was higher in ALK variant 1 cell line, H3122 $(68.7 \pm 21.1 \mathrm{nM})$ than in an ALK variant $3 \mathrm{a} / \mathrm{b}$ cell line, H2228 $(33.0 \pm 10.7 \mathrm{nM})(42)$. Therefore, we hypothesized that in ALK-positive group with low TS expression, the delicate difference in level of TS might not be the critical factor that determined the efficacy to pemetrexed when we stratified the ALK-positive patients into different ALK variants.

This study has several limitations that need to be acknowledged. Firstly, although we analyzed the largest cohorts of patients harboring ALK aberrations, the sample size in the cohort of patients with BM was relatively small. Only 33 patients were enrolled for the analysis of survival outcome and 35 patients included for the analysis of radiological features. Secondly, it is a single-institution study. Thirdly, the impact of second and third generation ALK-TKIs with improved CNS penetration on clinical outcomes in different ALK variants were not examined in this study. Additionally, given the nature of retrospective study, many confounding factors might have impact on drawing a convincing conclusion. Finally, due to a limited sample size of some of the less common variant subtypes, we had to analyze non-variant 1 as a conglomerate cohort. Therefore, the results need to be interpreted with caution.

\section{Conclusions}

In summary, our findings provide a possible explanation for the discrepancy between studies on crizotinib efficacy among ALK variants-that ALK variant 1 with BM had inferior TTF than non-variant 1 with BM due to more aggressive and frequent BMs. Moreover, ALK non-variant 1 had longer TTF than variant 1 in the chemotherapytreated group, which further strengthen the need to explore additional treatment strategies based on ALK variant in patients with ALK fusion.

\section{Acknowledgments}

We would like to thank Dr. Dong-wan Kim from Seoul National University for his critical comments on this study in 2018 World Conference on Lung Cancer held in Toronto, Canada.

Funding: This work was supported by grants from the National Natural Science Foundation of China (No. 81672286, 81871006, 81972169), National R\&D projects (2016YFC0902300), Shanghai Science and Technology
Medical Guidance Project (16411964400), Shanghai Science and Technology Innovative Project (19411950300).

\section{Footnote}

Reporting Checklist: The authors have completed the STROBE Reporting Checklist. Available at http://dx.doi. org/10.21037/tlcr-19-346

Data Sharing Statement: Available at http://dx.doi. org/10.21037/tlcr-19-346

Conflicts of Interest: All authors have completed the ICMJE uniform disclosure form (available at http://dx.doi. org/10.21037/tlcr-19-346). TJ serves as an unpaid editorial board member of Translational Lung Cancer Research from Feb 2018 to Feb 2021. CZ serves as an unpaid editorial board member of Translational Lung Cancer Research from Mar 2012 to Mar 2022. The other authors have no conflicts of interest to declare.

Ethical Statement: The authors are accountable for all aspects of the work in ensuring that questions related to the accuracy or integrity of any part of the work are appropriately investigated and resolved. The study was conducted in accordance with the Declaration of Helsinki (as revised in 2013) and was approved by the Ethics Committee of Shanghai Pulmonary Hospital, Tongji University School of Medicine (No. K18-089-1). Because of the retrospective nature of the research, the requirement for informed consent was waived.

Open Access Statement: This is an Open Access article distributed in accordance with the Creative Commons Attribution-NonCommercial-NoDerivs 4.0 International License (CC BY-NC-ND 4.0), which permits the noncommercial replication and distribution of the article with the strict proviso that no changes or edits are made and the original work is properly cited (including links to both the formal publication through the relevant DOI and the license). See: https://creativecommons.org/licenses/by-nc-nd/4.0/.

\section{References}

1. Soda M, Choi YL, Enomoto M, et al. Identification of the transforming EML4-ALK fusion gene in non-small-cell lung cancer. Nature 2007;448:561-6.

2. Vavalà T, Mariniello A, Novello S. Anaplastic lymphoma 
kinase tyrosine kinase inhibitors in non-small cell lung cancer. Transl Cancer Res 2019;8S48-54.

3. Shaw AT, Kim DW, Nakagawa K, et al. Crizotinib versus chemotherapy in advanced ALK-positive lung cancer. $\mathrm{N}$ Engl J Med 2013;368:2385-94.

4. Blackhall F, Ross Camidge D, Shaw AT, et al. Final results of the large-scale multinational trial PROFILE 1005: efficacy and safety of crizotinib in previously treated patients with advanced/metastatic ALK-positive nonsmall-cell lung cancer. ESMO Open 2017;2:e000219.

5. Delmonte A, Burgio MA, Verlicchi A, et al. New generation anaplastic lymphoma kinase inhibitors. Transl Lung Cancer Res 2019;8:S280-9.

6. Solomon BJ, Mok T, Kim DW, et al. First-line crizotinib versus chemotherapy in ALK-positive lung cancer. N Engl J Med 2014;371:2167-77.

7. Bender L, Meyer G, Quoix E, et al. Ceritinib-related interstitial lung disease improving after treatment cessation without recurrence under either crizotinib or brigatinib: a case report. Ann Transl Med 2019;7:106.

8. Johung KL, Yeh N, Desai NB, et al. Extended Survival and Prognostic Factors for Patients With ALK-Rearranged Non-Small-Cell Lung Cancer and Brain Metastasis. J Clin Oncol 2016;34:123-9.

9. Soria JC, Tan DSW, Chiari R, et al. First-line ceritinib versus platinum-based chemotherapy in advanced ALKrearranged non-small-cell lung cancer (ASCEND-4): a randomised, open-label, phase 3 study. Lancet 2017;389:917-29.

10. Shaw AT, Gandhi L, Gadgeel S, et al. Alectinib in ALKpositive, crizotinib-resistant, non-small-cell lung cancer: a single-group, multicentre, phase 2 trial. Lancet Oncol 2016;17:234-42.

11. Zhou C, Kim SW, Reungwetwattana T, et al. Alectinib versus crizotinib in untreated Asian patients with anaplastic lymphoma kinase-positive non-small-cell lung cancer (ALESIA): a randomised phase 3 study. Lancet Respir Med 2019;7:437-46.

12. Kim DW, Tiseo M, Ahn MJ, et al. Brigatinib in Patients With Crizotinib-Refractory Anaplastic Lymphoma KinasePositive Non-Small-Cell Lung Cancer: A Randomized, Multicenter Phase II Trial. J Clin Oncol 2017;35:2490-8.

13. Shaw AT, Felip E, Bauer TM, et al. Lorlatinib in nonsmall-cell lung cancer with ALK or ROS1 rearrangement: an international, multicentre, open-label, single-arm firstin-man phase 1 trial. Lancet Oncol 2017;18:1590-9.

14. Camidge DR, Kim HR, Ahn MJ, et al. Brigatinib versus Crizotinib in ALK-Positive Non-Small-Cell Lung Cancer.
N Engl J Med 2018;379:2027-39.

15. Zhang Y, Zhou H, Zhang L. Which is the optimal immunotherapy for advanced squamous non-small-cell lung cancer in combination with chemotherapy: anti-PD-1 or anti-PD-L1? J Immunother Cancer 2018;6:135.

16. Camidge DR, Kono SA, Lu X, et al. Anaplastic lymphoma kinase gene rearrangements in non-small cell lung cancer are associated with prolonged progression-free survival on pemetrexed. J Thorac Oncol 2011;6:774-80.

17. Choi YL, Takeuchi K, Soda M, et al. Identification of novel isoforms of the EML4-ALK transforming gene in non-small cell lung cancer. Cancer Res 2008;68:4971-6.

18. Takeuchi K, Choi YL, Soda M, et al. Multiplex reverse transcription-PCR screening for EML4-ALK fusion transcripts. Clin Cancer Res 2008;14:6618-24.

19. Heuckmann JM, Balke-Want H, Malchers F, et al. Differential protein stability and ALK inhibitor sensitivity of EML4-ALK fusion variants. Clin Cancer Res 2012;18:4682-90.

20. Lei YY, Yang JJ, Zhang XC, et al. Anaplastic Lymphoma Kinase Variants and the Percentage of ALK-Positive Tumor Cells and the Efficacy of Crizotinib in Advanced NSCLC. Clin Lung Cancer 2016;17:223-31.

21. Yoshida T, Oya Y, Tanaka K, et al. Differential Crizotinib Response Duration Among ALK Fusion Variants in ALKPositive Non-Small-Cell Lung Cancer. J Clin Oncol 2016;34:3383-9.

22. Cha YJ, Kim HR, Shim HS. Clinical outcomes in ALKrearranged lung adenocarcinomas according to ALK fusion variants. J Transl Med 2016;14:296.

23. Woo CG, Seo S, Kim SW, et al. Differential protein stability and clinical responses of EML4-ALK fusion variants to various ALK inhibitors in advanced ALKrearranged non-small cell lung cancer. Ann Oncol 2017;28:791-7.

24. Li Y, Zhang T, Zhang J, et al. Response to crizotinib in advanced ALK-rearranged non-small cell lung cancers with different ALK-fusion variants. Lung Cancer 2018;118:128-33.

25. Lin JJ, Zhu VW, Yoda S, et al. Impact of EML4-ALK Variant on Resistance Mechanisms and Clinical Outcomes in ALK-Positive Lung Cancer. J Clin Oncol 2018;36:1199206.

26. Mitiushkina NV, Tiurin VI, Iyevleva AG, et al. Variability in lung cancer response to ALK inhibitors cannot be explained by the diversity of ALK fusion variants. Biochimie 2018;154:19-24.

27. Pacheco JM, Gao D, Smith D, et al. Natural history and 
factors associated with overall survival in stage IV ALK rearranged non-small-cell lung cancer. J Thorac Oncol 2019;14:691-700.

28. Sperduto PW, Kased N, Roberge D, et al. Summary report on the graded prognostic assessment: an accurate and facile diagnosis-specific tool to estimate survival for patients with brain metastases. J Clin Oncol 2012;30:419-25.

29. Lee DW, Shin DY, Kim JW, et al. Additional prognostic role of EGFR activating mutations in lung adenocarcinoma patients with brain metastasis: integrating with lung specific GPA score. Lung Cancer 2014;86:363-8.

30. Ren S, Kuang P, Zheng L, et al. Analysis of driver mutations in female non-smoker Asian patients with pulmonary adenocarcinoma. Cell Biochem Biophys 2012;64:155-60.

31. Zhang L, Jiang T, Li X, et al. Clinical features of Bim deletion polymorphism and its relation with crizotinib primary resistance in Chinese patients with ALK/ROS1 fusion-positive non-small cell lung cancer. Cancer 2017;123:2927-35.

32. Wu C, Zhao C, Yang Y, et al. High Discrepancy of Driver Mutations in Patients with NSCLC and Synchronous Multiple Lung Ground-Glass Nodules. J Thorac Oncol 2015;10:778-83.

33. Wang Y, Zhang J, Gao G, et al. EML4-ALK Fusion Detected by RT-PCR Confers Similar Response to Crizotinib as Detected by FISH in Patients with Advanced Non-Small-Cell Lung Cancer. J Thorac Oncol 2015;10:1546-52.

34. Wang Y, Liu Y, Zhao C, et al. Feasibility of cytological specimens for ALK fusion detection in patients with advanced NSCLC using the method of RT-PCR. Lung Cancer 2016;94:28-34.

Cite this article as: Qiao M, Zhao C, Liu Q, Wang Y, Shi J, Ng TL, Zhou F, Li X, Jiang T, Yang S, Gao G, Xiong A, Li J, Li W, Wu F, Chen X, Su C, Ren S, Zhou C, Zhang J. Impact of ALK variants on brain metastasis and treatment response in advanced NSCLC patients with oncogenic ALK fusion. Transl Lung Cancer Res 2020;9(4):1452-1463. doi: 10.21037/tlcr-19-346
35. Ng TL, Liu Y, Dimou A, et al. Predictive value of oncogenic driver subtype, programmed death-1 ligand (PD-L1) score, and smoking status on the efficacy of PD-1/PD-L1 inhibitors in patients with oncogene-driven non-small cell lung cancer. Cancer 2019;125:1038-49.

36. Fábián K, Gyulai M, Furak J, et al. Significance of Primary Tumor Location and Histology for Brain Metastasis Development and Peritumoral Brain Edema in Lung Cancer. Oncology 2016;91:237-42.

37. Pope WB, Sayre J, Perlina A, et al. MR imaging correlates of survival in patients with high-grade gliomas. AJNR Am J Neuroradiol 2005;26:2466-74.

38. Chen G, Chen X, Zhang Y, et al. A large, single-center, real-world study of clinicopathological characteristics and treatment in advanced ALK-positive non-small-cell lung cancer. Cancer Med 2017;6:953-61.

39. Xing $\mathrm{P}$, Wang S, Hao X, et al. Clinical data from the real world: efficacy of Crizotinib in Chinese patients with advanced ALK-rearranged non-small cell lung cancer and brain metastases. Oncotarget 2016;7:84666-74.

40. Lei YY, Yang JJ, Zhong WZ, et al. Clinical efficacy of crizotinib in Chinese patients with ALK-positive nonsmall-cell lung cancer with brain metastases. J Thorac Dis 2015;7:1181-8.

41. Ren S, Chen X, Kuang P, et al. Association of EGFR mutation or ALK rearrangement with expression of DNA repair and synthesis genes in never-smoker women with pulmonary adenocarcinoma. Cancer 2012;118:5588-94.

42. Lee JO, Kim TM, Lee SH, et al. Anaplastic lymphoma kinase translocation: a predictive biomarker of pemetrexed in patients with non-small cell lung cancer. J Thorac Oncol 2011;6:1474-80. 

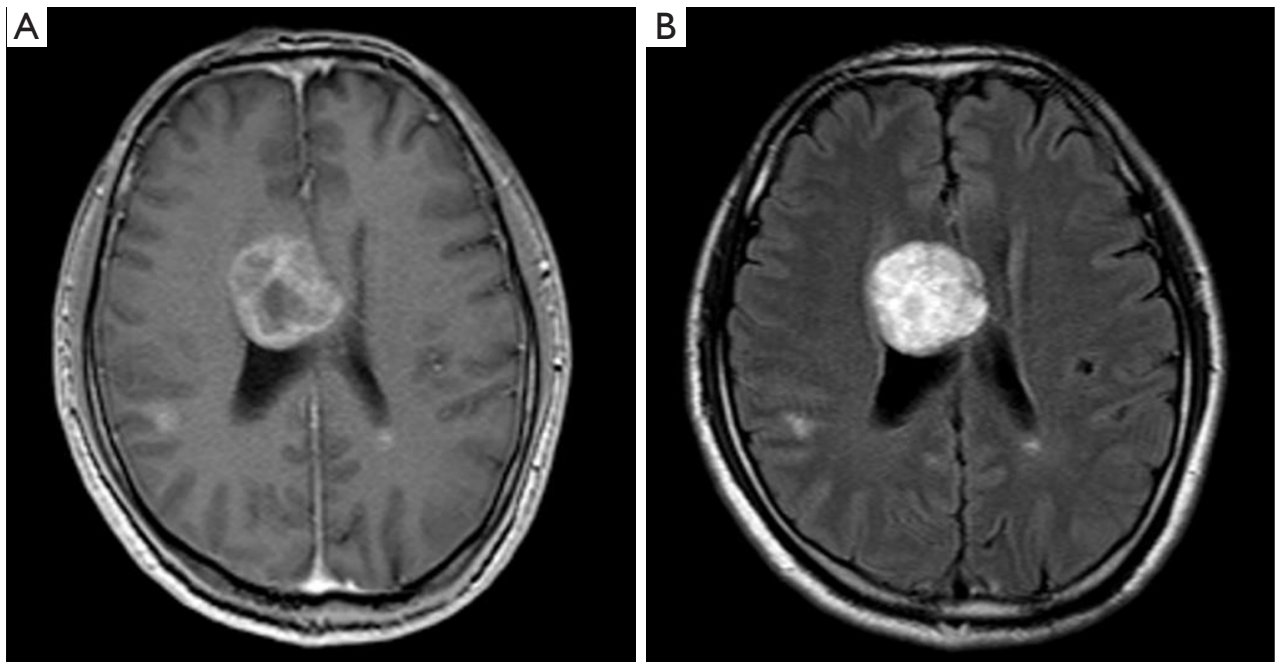

Figure S1 Tumor located in right lateral ventricle on T1-weighted image (A) compared to T2-weighted image demonstrates absence of PTBE (B).

Table S1 Clinical characteristics of included patients with BM

\begin{tabular}{|c|c|c|c|c|}
\hline Characteristic & Total $(\mathrm{N}=33)(\%)$ & Variant $1(\mathrm{~N}=15)(\%)$ & Non-variant 1 (N=18) (\%) & $P$ value \\
\hline Gender & & & & 0.126 \\
\hline Male & $15(45.5)$ & $9(60.0)$ & $6(33.3)$ & \\
\hline Female & $18(54.5)$ & $6(40.0)$ & $12(66.7)$ & \\
\hline Adenocarcinoma & $30(90.9)$ & $13(86.7)$ & $17(94.4)$ & \\
\hline Non-adenocarcinoma & $3(9.1)$ & $2(13.3)$ & $1(5.6)$ & \\
\hline Smoking status & & & & 0.748 \\
\hline Current/former smokers & $9(27.3)$ & $5(33.3)$ & $4(22.2)$ & \\
\hline Unresected IIIB-IV & $31(93.9)$ & 14 (93.3) & $17(94.4)$ & \\
\hline Postoperative recurrent & $2(6.1)$ & $1(6.7)$ & $1(5.6)$ & \\
\hline First-line treatment strategy & & & & 0.126 \\
\hline Chemotherapy & $15(45.5)$ & $9(60.0)$ & $6(33.3)$ & \\
\hline Crizotinib & $18(54.5)$ & $6(40.0)$ & $12(66.7)$ & \\
\hline
\end{tabular}


Table S2 The objective response (ORR) and disease control rate (DCR) in group of variant 1 and non-variant 1 treated with crizotinib

\begin{tabular}{|c|c|c|c|c|c|c|c|c|c|}
\hline RECIST & \multicolumn{3}{|c|}{ Total } & \multicolumn{3}{|c|}{ First-line } & \multicolumn{3}{|c|}{ Non-first line } \\
\hline SD & 12 & 13 & & 7 & 8 & & 5 & 5 & \\
\hline DCR (\%) & 95.2 & 87.2 & 0.344 & 93.3 & 88.6 & 0.817 & 100 & 83.3 & 0.478 \\
\hline
\end{tabular}

\begin{tabular}{|c|c|c|c|c|c|c|c|c|c|c|c|c|}
\hline \multirow[b]{2}{*}{ PR } & \multirow[t]{2}{*}{ Va } & Non-variant $1(n=18)$ & & & & & & & & & & \\
\hline & & & & \multirow[b]{2}{*}{$\begin{array}{r}\text { variant } 1 \\
(n=15) \\
\end{array}$} & \multirow{2}{*}{$\begin{array}{l}\text { Total } \\
\text { non-variant } 1 \\
(n=18)\end{array}$} & \multirow[b]{2}{*}{$\begin{array}{c}p \\
\text { value }\end{array}$} & \multicolumn{2}{|c|}{ Crizotinib } & \multicolumn{4}{|c|}{ Chemotherapy } \\
\hline & & & & & & & $\begin{array}{c}\text { variant } 1 \\
(n=6)\end{array}$ & $\begin{array}{c}\text { non-variant } 1 \\
(n=12)\end{array}$ & $\begin{array}{c}\mathrm{p} \\
\text { value }\end{array}$ & $\begin{array}{c}\text { variant } 1 \\
(n=9)\end{array}$ & $\begin{array}{c}\text { non-variant } 1 \\
(n=6)\end{array}$ & $\begin{array}{c}\mathrm{p} \\
\text { value } \\
\end{array}$ \\
\hline & & & PR & 3 & 12 & & 3 & 9 & & 0 & 3 & \\
\hline & & & PD & 2 & 0 & & 0 & 0 & & 2 & 0 & \\
\hline D & & & ORR $(\%)$ & 20.0 & 66.7 & 0.007 & 50.0 & 75.0 & 0.596 & 0.0 & 50.0 & 0.087 \\
\hline
\end{tabular}

Figure S2 The objective response rate (ORR) in ALK+ patients with baseline brain metastasis.

Table S3 ORR and DCR in group of variant 1 and non-variant 1 treated with chemotherapy

\begin{tabular}{lccc}
\hline RECIST & Variant $1(\mathrm{n}=31)$ & Non-variant 1 $(\mathrm{n}=39)$ & $\mathrm{P}$ value \\
\hline PR & 6 & 14 & 18 \\
SD & 15 & 7 & \\
PD & 10 & 35.9 & 0.128 \\
ORR (\%) & 19.4 & 82.1 & 0.165 \\
DCR (\%) & 67.7 & 8 & \\
\hline
\end{tabular}

Table S4 Progression pattern between variant 1 and non-variant 1 in face of different treatment strategies

\begin{tabular}{|c|c|c|c|c|}
\hline \multirow{2}{*}{ Progression pattern } & \multicolumn{2}{|c|}{ Crizotinib $(n=55)$} & \multicolumn{2}{|c|}{ Chemotherapy $(n=61)$} \\
\hline & Variant 1 (n=28) & Non-variant $1(\mathrm{n}=27)$ & Variant $1(\mathrm{n}=28)$ & Non-variant $1(n=33)$ \\
\hline Bone progression & $3(10.7)$ & $0(0)$ & $3(10.7)$ & $8(24.2)$ \\
\hline Liver progression & $1(3.6)$ & $0(0)$ & $1(3.6)$ & $2(6.1)$ \\
\hline Other extrathoracic progression & $1(3.6)$ & $4(14.8)$ & $0(0)$ & $2(6.3)$ \\
\hline
\end{tabular}


A

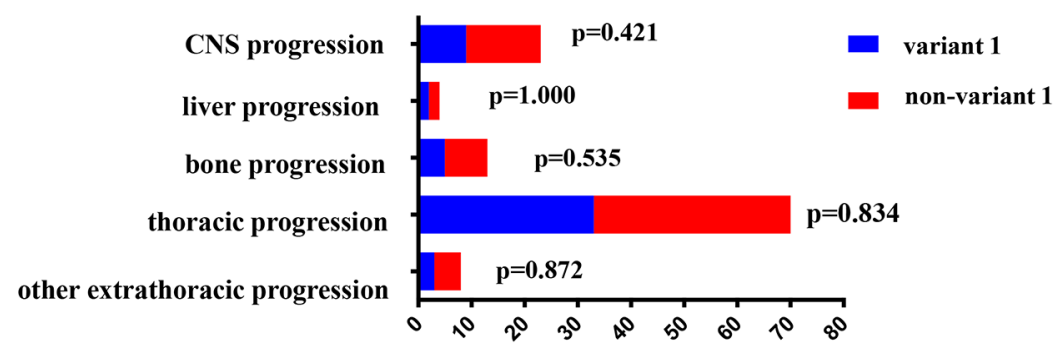

B

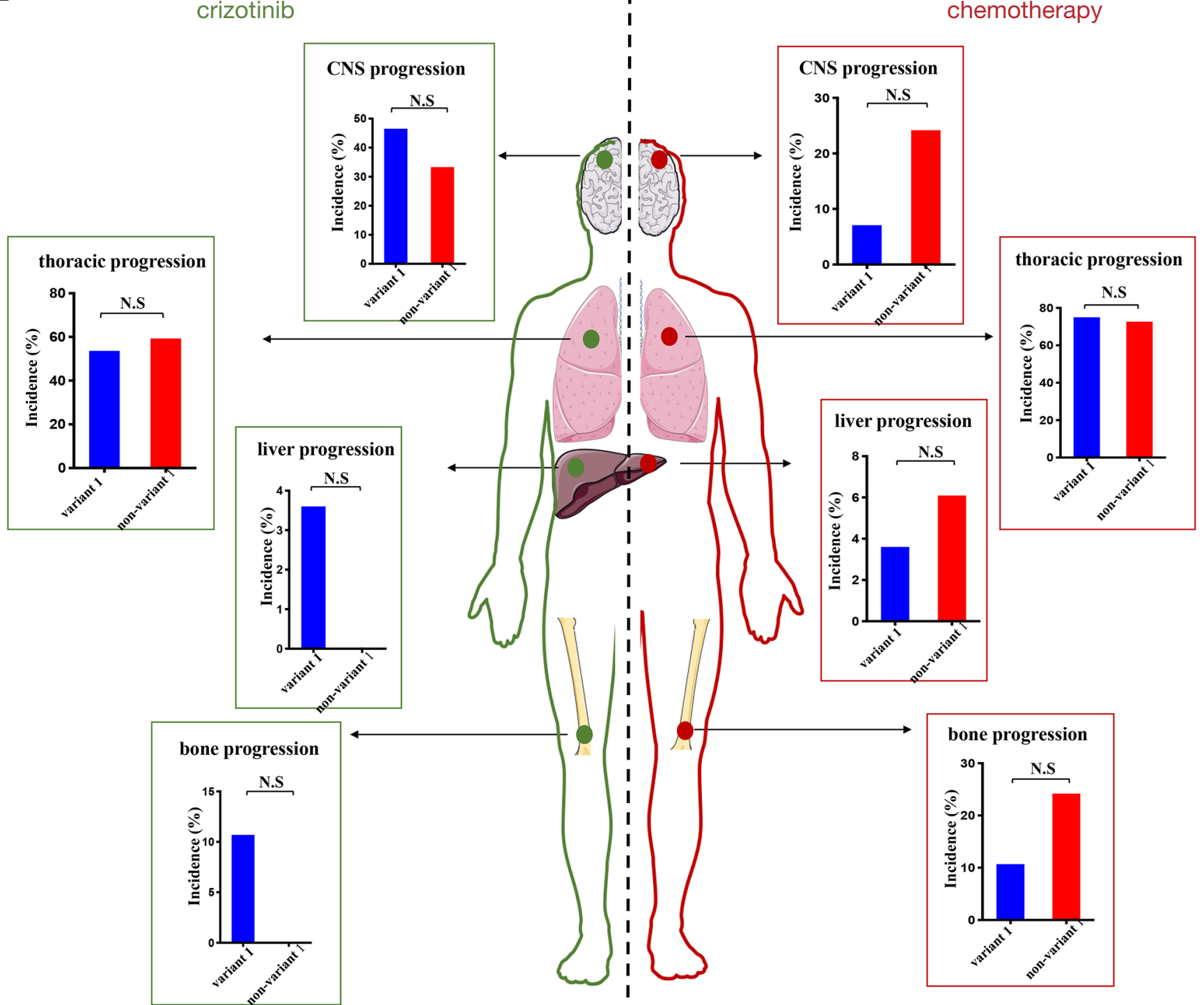

Figure S3 Progression pattern in overall population stratified by (A) ALK variant, (B) treatment strategy (crizotinib versus chemotherapy). 
Table S5 Previous studies about the impact of ALK variants on treatment response

\begin{tabular}{|c|c|c|c|c|c|c|}
\hline Author & Year & Study design & $\begin{array}{l}\text { Methods for genotyping } \\
\text { ALK variants }\end{array}$ & Proportion of ALK variants & Results & Reference \\
\hline Heuckmann & 2012 & $\begin{array}{l}\text { In vitro experiments conducted to analyze } \\
\text { the cytotoxic efficacy of crizotinib on } \\
\text { different ALK variants by making Ba/F3 cell- } \\
\text { line model }\end{array}$ & - & - & $\begin{array}{l}\text { EML4-ALK variant } 2 \text { was the most } \\
\text { sensitive variant to the crizotinib in vitro }\end{array}$ & (19) \\
\hline Lei & 2015 & $\begin{array}{l}\text { A retrospective study conducted on } 61 \\
\text { patients treated with crizotinib }\end{array}$ & $\begin{array}{l}\text { rapid amplification of } \\
\text { cDNA ends (RACE)- } \\
\text { coupled PCR }\end{array}$ & & $\begin{array}{c}\text { No significant difference existed among } \\
\text { three groups }\end{array}$ & (20) \\
\hline Yoshida & 2016 & $\begin{array}{l}\text { A retrospective study conducted on } 35 \\
\text { patients treated with crizotinib }\end{array}$ & RT-PCR & & $\begin{array}{l}\text { Varaint } 1 \text { had better PFS than non- } \\
\text { variant } 1 \text { (median PFS: } 11 \text { vs. } 4.2 \text { months, } \\
\qquad P<0.05 \text { ) }\end{array}$ & $(21)$ \\
\hline Cha & 2016 & $\begin{array}{l}\text { A retrospective study conducted on } 52 \\
\text { patients who have once treated with ALK } \\
\text { inhibitors or chemotherapy }\end{array}$ & $\begin{array}{l}\text { PNA-mediated qPCR } \\
\text { assay }\end{array}$ & & $\begin{array}{c}\text { Variant } 1 \text { had superior PFS than other } \\
\text { variants in patients once treated with } \\
\text { pemetrexed }\end{array}$ & (22) \\
\hline Woo & 2016 & $\begin{array}{c}\text { A retrospective study conducted on } 54 \\
\text { patients once treated with ALK inhibitors } \\
\text { together with experients in vitro by making } \\
\mathrm{Ba} / \mathrm{F} 3 \text { and Beas-2B cell lines }\end{array}$ & $\begin{array}{l}\text { PNA-mediated qPCR } \\
\text { assay }\end{array}$ & & $\begin{array}{c}\text { 2-year PFS had no difference among } \\
\text { variant } 1 / 2 \text { /others or variant } 3 \text { treated with } \\
\text { crizotinib }(P=0.108) \\
\text { Variant } 3 a / \text { variant } 5 \text { a were resistant to } \\
\text { ALK inhibitors in vitro }\end{array}$ & (23) \\
\hline $\mathrm{Li}$ & 2017 & $\begin{array}{l}\text { A retrospective study conducted on } 35 \\
\text { patients treated with crizotinib }\end{array}$ & targeted NGS & & $\begin{array}{l}\text { Variant } 2 \text { had prolonged PFS }(\mathrm{P}=0.021) \\
\text { Variant } 3 \mathrm{a} / \mathrm{b} \text { and non-variant } 3 \mathrm{a} / \mathrm{b} \text { had no } \\
\text { PFS difference }\end{array}$ & (24) \\
\hline Lin & 2018 & $\begin{array}{c}\text { A retrospective study conducted on } 129 \\
\text { patients treated ALK inhibitors including } \\
55 \text { patients received crizotinib as first-line } \\
\text { therapy }\end{array}$ & targeted NGS & & $\begin{array}{l}\text { Similar PFS was observed while } \\
\text { comparing patients with variant } 1 \text { or } \\
\text { varaint } 3 \text { treated with crizotinib }(P=0.163)\end{array}$ & (25) \\
\hline Mitiushkina & 2018 & $\begin{array}{l}\text { A retrospective study conducted on } 64 \\
\text { patients treated ALK inhibitors }\end{array}$ & RT-PCR & & $\begin{array}{l}\text { Similar PFS was observed while } \\
\text { comparing variant } 1 \text { and non-variant } 1 \\
\qquad(\mathrm{P}=0.604)\end{array}$ & (26) \\
\hline
\end{tabular}

